\title{
A Day in the Death of a Hospice Patient
}

\author{
J. Trig Brown, MD, MPH
}

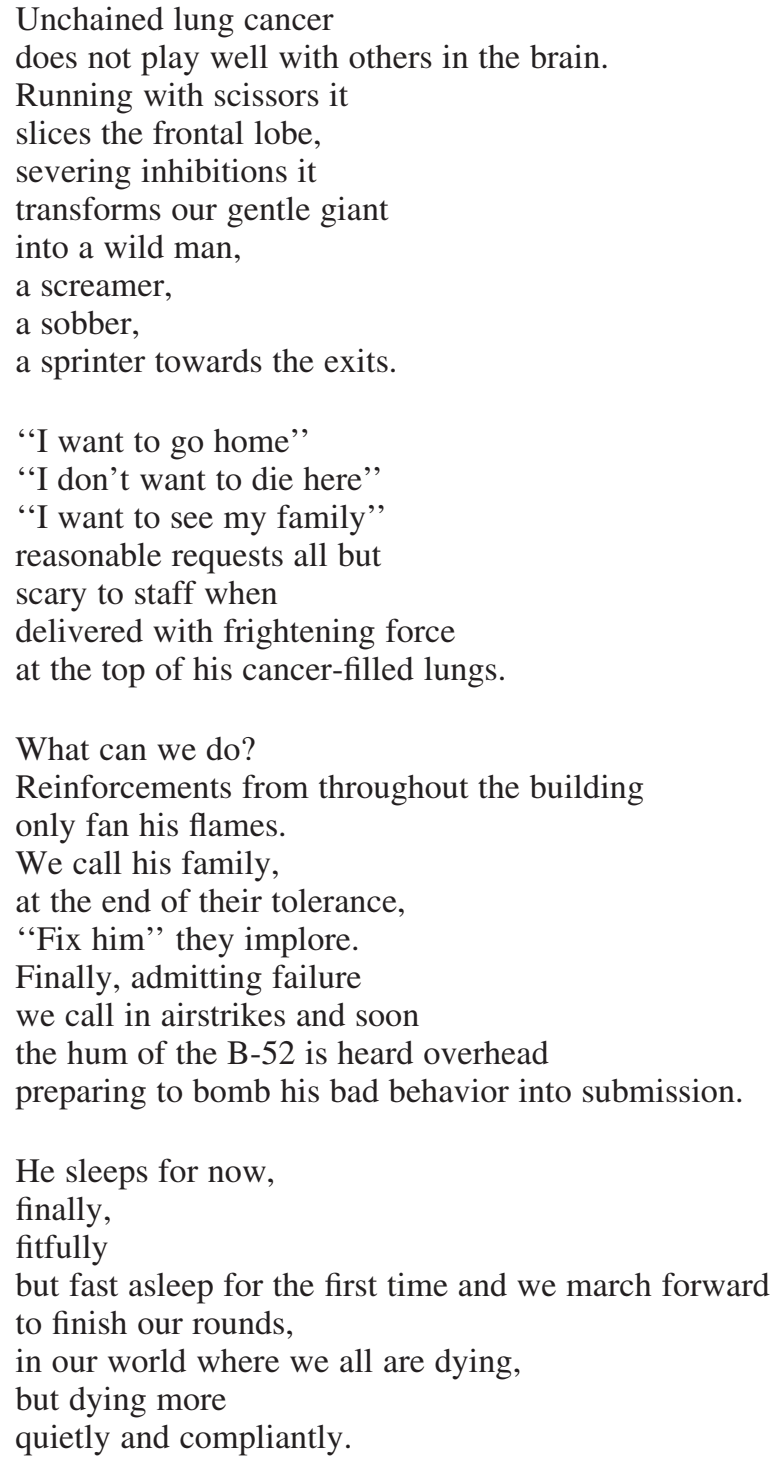

What can we do?

Reinforcements from throughout the building only fan his flames.

We call his family,

at the end of their tolerance,

"Fix him" they implore.

Finally, admitting failure

we call in airstrikes and soon

the hum of the B-52 is heard overhead

preparing to bomb his bad behavior into submission.

He sleeps for now,

finally,

fitfully

but fast asleep for the first time and we march forward

to finish our rounds,

in our world where we all are dying,

but dying more

quietly and compliantly.

Address correspondence to: 